Proceedings of the XXIII Conference on Applied Crystallography, Krynica Zdrój, Poland, September 20-24, 2015

\title{
Influence of High Energy Milling Time on the Ti-50Ta Biomedical Alloy Structure
}

\author{
I. Matula, G. Dercz*, M. Zubko, K. Prusik and L. PająK \\ Institute of Materials Science, University of Silesia, 75 Pułku Piechoty 1A, 41-500 Chorzów, Poland \\ Nickel-free titanium alloys are a promising research direction in the field of biomedical materials. Current \\ literature reports indicate that there is a possibility of using the $\mathrm{Ti}-\mathrm{Ta}$ alloys in medicine since these alloys have \\ had satisfactory results as far as biocompatibility, resistance to corrosion and mechanical properties are concerned, \\ which is an important aspect while considering the use of this alloy for long-lasting bone implants. This article \\ presents the results of a high-energy milling process with the use of $\mathrm{Ti}$ and Ta powders. The ball-milling process \\ was carried out for various times, including $20,40,60,80$, and $100 \mathrm{~h}$. The samples were characterized by X-ray \\ diffraction, scanning electron microscopy, and transmission electron microscopy. The research confirmed partial \\ synthesis of the materials during the process of high energy ball milling.
}

DOI: 10.12693/APhysPolA.130.1033

PACS/topics: 87.85.J-, 81.05.Zx, 81.07.Wx, 81.20.Ev

\section{Introduction}

Titanium-based alloys are a very attractive material for biomedical applications, in particular for long-lasting bone implants. The advantages of this material such as: high biocompatibility, very high resistance to corrosion, ability to self-passivate, low thermal conduction and high mechanical strength contribute to the fact that this material is widely used in medicine. In addition, titaniumbased alloys have lower density and the lowest Young modulus in comparison to other metals currently used for medical implants [1]. Unfortunately, research has shown that some of the alloying additives like $\mathrm{Al}, \mathrm{V}, \mathrm{Ni}$ are toxic and pose a threat to the patients' health and life. This results in the continuous development of the research into the effect that the alloying additives of greater biocompatibility $(\mathrm{Ta}, \mathrm{Nb})$ have on the structure and properties of the alloy. Due to the lack of cytotoxicity, high tendency to self-passivate and chemical resistance tantalum is one of the more promising additives used to modify titanium [2]. Tantalum is an alloy additive which will decrease the temperature of the martensite transformation, which - as a result - causes the expansion of the scope of the $\beta$ phase in titanium-based alloys. The research has also confirmed that the addition of tantalum can inhibit the occurrence of undesirable phases such as the $\omega$ metastable phase $[3,4]$. The corrosion resistance of the $\mathrm{Ti}-\mathrm{Ta}$ alloys is higher than the corrosion resistance of pure titanium or titanium-based alloys currently used in medicine [5]. The decisive advantage of $\mathrm{Ti}-\mathrm{Ta}$ alloys in the aspect of biomedical alloys are their mechanical properties. The Ti-Ta alloy elasticity modulus is significantly lower than the value of the modulus of the alloys currently used for implants. At the same time the tensile strength value is comparable to value of pure titanium and the cobalt based alloys [6-8]. Production of an alloy

\footnotetext{
*corresponding author; e-mail: grzegorz.dercz@us.edu.pl
}

belonging to the $\mathrm{Ti}-\mathrm{Ta}$ alloy using traditional methods poses difficulties due to high differences in melting points (about $1350{ }^{\circ} \mathrm{C}$ ) and significant difference in the density of pure elements (Ti: $4.51 \mathrm{~g} / \mathrm{cm}^{3}$, Ta: $16.6 \mathrm{~g} / \mathrm{cm}^{3}$ ), which can be the reason, among others, for the presence of component high segregation confirmed by current literature reports [9]. Results of the research carried out by Liu et al. into the synthesis of $\mathrm{Ti}-\mathrm{Ta}$ alloys using the powder metallurgy (PM) have shown that the material is heterogeneous with distinct zones enriched in the output elements regardless of the alloy composition and the temperature of the synthesis [9]. Therefore in this study, it seems justified to use the mechanical alloying method in a high energy mill for the synthesis of the Ti-50Ta alloy (wt\%) and then examine how the milling process affects the structure of this alloy.

\section{Experimental details}

Commercial powders such as Ti (Atlantic Equipment Engineers (AEE), 99.7\%, -625 mesh $(<20 \mu \mathrm{m}))$ and Ta (Sigma Aldrich, 99.9\%, -325 mesh $(<44 \mu \mathrm{m}))$ were used as initial powder for the synthesis of the alloy. Equilibrium weighted amounts corresponding to the Ti50Ta alloy (wt\%) were prepared. They underwent the high-energy planetary-ball milling in the Fritch PULVERISETTE 7 premium line mill. The containers and balls that were used were made of hardened steel. The process parameters were as follows: milling speed was $250 \mathrm{rpm}$ and the weight ratio of the balls to the material was 10:1. The milling time was a variable technological parameter and was 20,40,60,80, and $100 \mathrm{~h}$ for the respective samples, and the powder was filled up afresh each time.

The crystalline structure and phase content of the obtained milled and sintered materials were tested by X-ray diffraction (XRD). The refinement of the XRD pattern was carried out using the Rietveld whole X-ray profile fitting technique with the DBWS 9807a program [10]. The profile function used to adjust the 
calculated diffractograms to the observed ones was the pseudo-Voigt one $[11,12]$. The weight fraction of each component was determined based on the optimized scale factors with the use of the relation proposed by Hill and Howard, and Dercz et al. [13, 14]. The crystallite sizes of the $\alpha$ and $\beta$ phases were estimated using the WilliamsonHall method [15]. The size of the crystallites and the lattice distortion were measured by the Willamson-Hall method. Verification tests of the crystallites were conducted using the electron transmission microscope JEM 3010 operating at the accelerating voltage of $300 \mathrm{kV}$. The morphology of the samples was tested using the scanning microscope JEOL JSM 6480 with the accelerating voltage of $20 \mathrm{kV}$. Chemical analysis was performed using the EDS detector manufactured by IXRF using the traditional/standard calibration method.

\section{Results and discussion}

The morphology of the powders at individual milling stages is shown in Fig. 1. SEM images of the powders milled for 20 and $40 \mathrm{~h}$ showed the creation of agglomerates as a result of the cold welding of powders and interconnection between particles (Fig. 1). The powder with the shortest milling time shows globular particles characteristic of plastic materials. In contrast, for the samples after $40 \mathrm{~h}$ of milling, the shape of the particle was changed and became more like that of a mica (Fig. 1), which proves an increase of the stress accompanied by increased brittleness [16]. At this stage, the distribution of the particle dispersion is very wide and is between 10 and $200 \mu \mathrm{m}$. In addition, for the powder
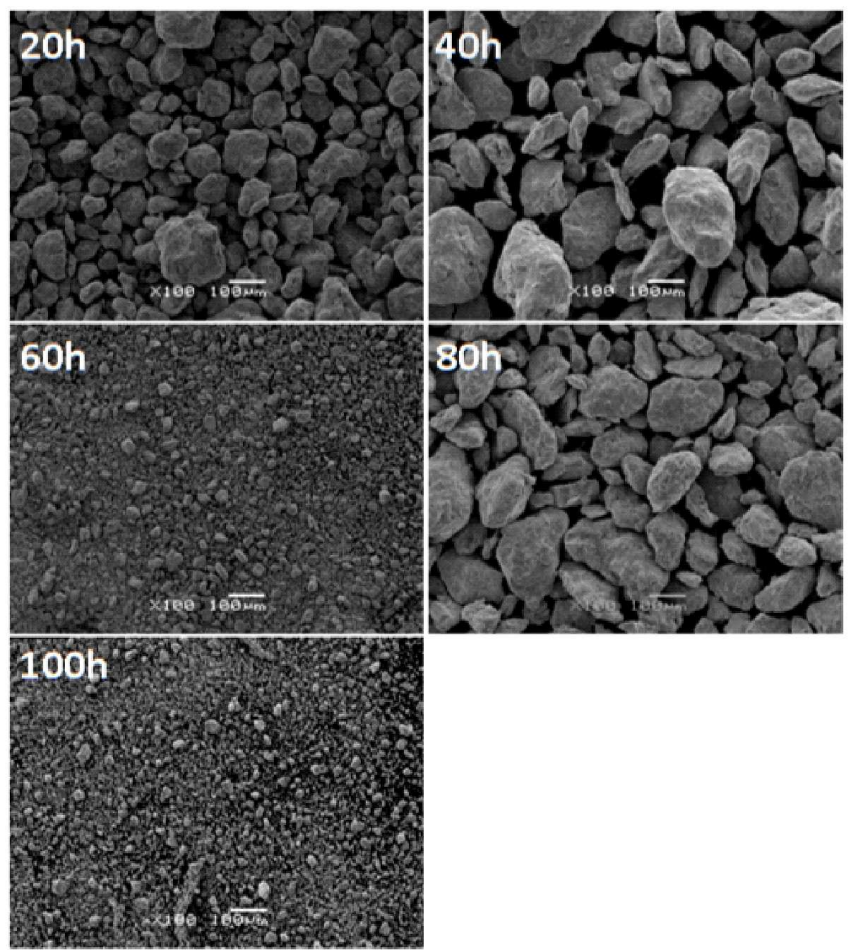

Fig. 1. SEM micrographs of powders ball-milled for 20, $40,60,80$, and $100 \mathrm{~h}$, respectively. after $40 \mathrm{~h}$ of milling, further growth of the particles and the cold welding on the milling balls were observed. For the sample after $60 \mathrm{~h}$ of milling a significant increase of the particle dispersion was observed. For the subsequent milling times of $80 \mathrm{~h}$ and $100 \mathrm{~h}$ cold welding and a growth of the particles as well as their fragmentation due to the milling processes were observed. This trend is consistent with the milling mechanisms of the two plastic materials.

SEM images of the cross-section of the ball used for $20 \mathrm{~h}$ milling with the cold welded material (Fig. 2) revealed further stages and processes which occur during the successive cold welding of the material onto the balls. The distribution map of the elements confirmed layered welding of the material enriched in one of the primary elements. It was concluded that an increase of the milling time causes greater fragmentation of the powder and a decrease of the concentration areas of one element at the same time. Observations of the micro-section revealed that at the end of $20 \mathrm{~h}$ of mechanical milling there appears a mechanical synthesis of the primary elements.

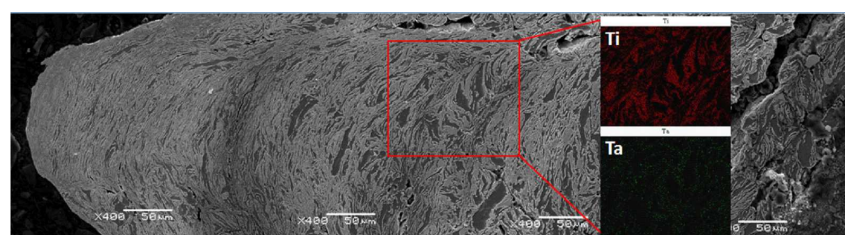

Fig. 2. The cross-section of the milling product obtained during a $20 \mathrm{~h}$ milling process with the distribution of Ti (red colour) and Ta (green colour) elements.

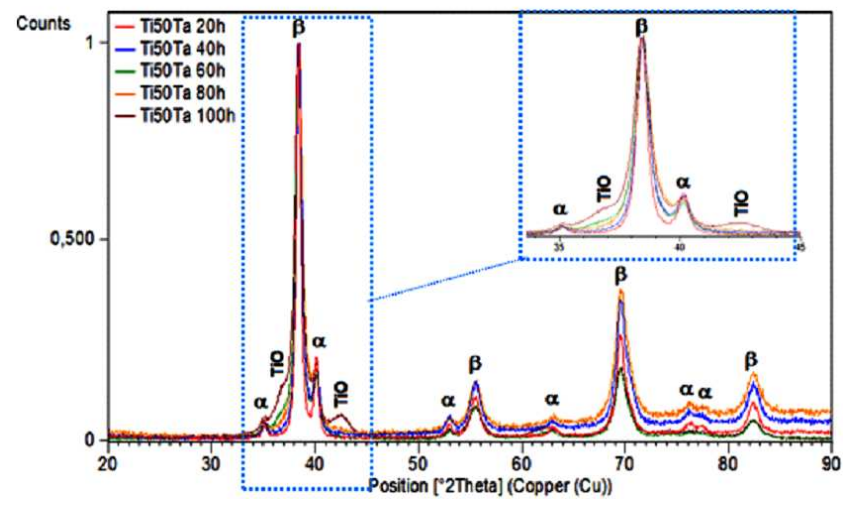

Fig. 3. X-ray diffraction patterns of Ti and Ta mixture after $20,40,60,80$, and $100 \mathrm{~h}$ of milling (subject to normalization in relation to the strongest reflex).

Figure 3 shows the results of the X-ray phase qualitative analysis for the powders at different milling stages. All XRD patterns revealed the $\alpha$ and $\beta$ phases. In addition, the diffraction pattern recorded for the $100 \mathrm{~h}$ milling time sample revealed the presence of $\mathrm{TiO}$, which may indicate the surface oxidation of the batch.

Detailed analysis by the Rietveld method allowed to determine the structural parameters and perform the quantitative phase analysis. Table I presents lattice parameters determined for individual phases and the 
corresponding ICDD data sheets. It was observed that high-energy milling has influence on the lattice parameters. In the case of the $\alpha$ phase their slightly but constant in its value deviation from the $a_{0}$ parameter catalogue data was observed. Furthermore, a clear decrease of the values of the lattice parameters on the $Z$ axis was observed. It should be stressed that for the sample after $80 \mathrm{~h}$ of milling a deviation for both lattice parameters can be noted down. It is probably the effect of an alternate cold welding and deposition of the particles during mechanical synthesis. In the case of $\beta$ phase it was observed that synthesis caused the expansion of the lattice, regardless of the milling time. The $a_{0}$ parameter value was constant. The expansion of the lattice results from the higher value of the tantalum lattice parameter in relation to $\beta$-titanium. The quantitative phase analysis of the material after each stage shows successive progressive synthesis of the as-prepared powders in relation to the $\beta$ phase $(80.2(5) \mathrm{wt} \%$ and $90.8(4) \mathrm{wt} \%$, respectively for $20 \mathrm{~h}$ and $80 \mathrm{~h}$ milling time). Unfortunately, due to the presence of the $\mathrm{TiO}$ phase in the longest milling cycle, it is impossible to unambiguously present the tendency to change for all milling times.

TABLE I

Lattice parameters $[\AA]$ of $\alpha(\mathrm{Ti}, \mathrm{Ta})$ and $\beta(\mathrm{Ta}, \mathrm{Ti})$ phases of the milled and annealed samples.

\begin{tabular}{c|c|c|c|c|c|c|c}
\hline \hline Phase & Lattice & ICDD & \multicolumn{5}{|c}{ Milling time [h] } \\
\cline { 4 - 7 } & param. & & 20 & 40 & 60 & 80 & 100 \\
\hline \multirow{2}{*}{$\alpha$} & $a_{0}$ & 2.950 & $2.951(1)$ & $2.956(1)$ & $2.952(1)$ & $2.964(2)$ & $2.952(1)$ \\
& $c_{0}$ & 4.683 & $4.678(3)$ & $4.672(5)$ & $4.678(3)$ & $4.645(8)$ & $4.666(3)$ \\
$\beta$ & $a_{0}$ & 3.283 & $3.308(1)$ & $3.308(1)$ & $3.308(3)$ & $3.308(1)$ & $3.307(1)$ \\
\hline
\end{tabular}

*International Centre for Diffraction Data ${ }^{\mathbb{R}}$

TABLE II

Changes of average crystallite size $D[\mathrm{~nm}]$ and lattice distortion $\langle\Delta a / a\rangle\left[10^{-3} \%\right]$ of $\alpha$ and $\beta$ phases of the milled samples.

\begin{tabular}{c|c|c|c|c|c|c}
\hline \hline \multirow{2}{*}{ Phase } & \multirow{2}{*}{ Parameter } & \multicolumn{5}{|c}{ Milling time $[\mathrm{h}]$} \\
\cline { 3 - 7 }$\alpha$ & $D$ & $16(2)$ & $8(1)$ & $10(1)$ & $6(1)$ & $8(1)$ \\
& $\langle\Delta a / a\rangle$ & 2.24 & 4.47 & 3.69 & 4.05 & 4.70 \\
\multirow{2}{*}{$\beta$} & $D$ & $27(2)$ & $17(2)$ & $21(2)$ & $11(1)$ & $11(1)$ \\
& $\langle\Delta a / a\rangle$ & 3.57 & 2.77 & 3.59 & 1.97 & 1.16
\end{tabular}

Based on the Williamson-Hall method the crystallite sizes $(D)$ for the phases appearing in the material at various milling stages were determined. The apparatus factors were eliminated by using $\mathrm{LaB}_{6}$ (SRM 660a). It was concluded that after each milling time/stage the nanocrystalline material was obtained. For the $\alpha$ phase it was observed that an increase in the dispersion of crystallites took place simultaneously with an increase of the milling time, finally reaching $8 \mathrm{~nm}$ after $100 \mathrm{~h}$ of milling (Table II). In addition, in the case of the $\alpha$ phase there appeared a tendency to decrease the lattice deformations $\langle\Delta a / a\rangle$. However, it must be stressed that for the milling time of $40 \mathrm{~h}$ for the $\alpha$ phase a significant increase in the $\langle\Delta a / a\rangle$ parameter was observed, which is likely to result from an increase in plastic deformations. For the $\beta$ phase an increase in the dispersion of crystallites was observed. However, in the case of the two longest milling times only a decrease of the $\langle\Delta a / a\rangle$ parameter, with a constant $D$ value, was observed (Table II).

Images in the bright and dark fields, as well as the diffraction image formed with the use of the transmission electron microscopy confirmed the nanocrystalline nature of the material (Fig. 4). Sample images of the powder milled in the bright and dark field for $60 \mathrm{~h}$ prove that a single particle of the powder is composed of many smaller crystallites with different orientations (Fig. 4).

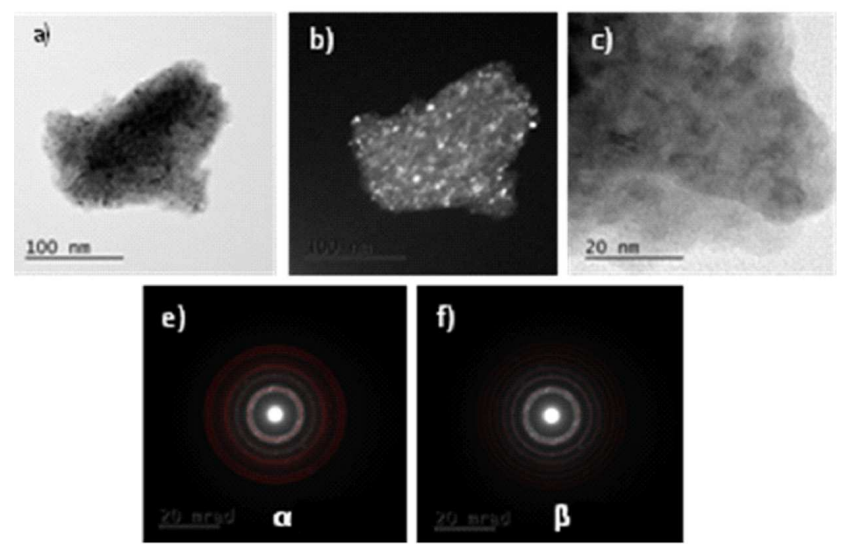

Fig. 4. TEM analysis of $\alpha$ and $\beta$ phases after a $60 \mathrm{~h}$ milling process presents bright-field (a), dark-field (b), HRTEM (c) and SAD patterns (e) and (f).

\section{Conclusion}

Based on the results obtained from the research into the $\mathrm{Ti}-50 \mathrm{Ta}$ (wt\%) prepared in a high energy milling process, the following conclusions can be drawn:

- The effect of the high-energy milling time of the substrates on the structure and phase composition of the Ti-50Ta (wt\%) alloy was observed.

- Partial synthesis of two $\alpha$ and $\beta$ phases was observed in the milled materials. It was found that the milling process causes an alternate increase and decrease of the particles with simultaneous decrease of the crystallite size of the $\beta$ and $\alpha$ phases. Moreover, from the cross-section analysis of the material from the ball surface, it was found that the synthesis of the initial components begins before $20 \mathrm{~h}$ of milling elapse.

- The study of the material obtained after milling shows the presence of a two-phase material, where $\beta$ phase is the main component of the tested materials. 


\section{Acknowledgments}

This work was supported by the Polish National Science Centre (NCN) under the research project no. UMO2011/03/D/ST8/04884.

\section{References}

[1] G. He, M. Hagiwara, Mater. Sci. Eng. C 26, 14 (2006).

[2] M. Sowa, A. Kazek-Kęsik, R.P. Socha, G. Dercz, J. Michalska, W. Simka, Electrochim. Acta 114, 627 (2013).

[3] A. Biesiekierski, J. Wang, M.A.-H. Gepreel, C. Wen, Acta Biomater. 8, 1661 (2012).

[4] P.J.S. Buenconsejo, H.Y. Kim, H. Hosoda, S. Miyazaki, Acta Mater. 57, 1068 (2009).

[5] D. Mareci, R. Chelariu, D.-M. Gordin, G. Ungureanu, T. Gloriant, Acta Biomater. 5, 3625 (2009).

[6] Y.-L. Zhou, M. Niinomi, Mater. Sci. Eng. C 29 , 1061 (2009)
[7] Y.-L. Zhou, M. Niinomi, J. Alloys Comp. 466, 535 (2008).

[8] Y.-L. Zhou, M. Niinomi, T. Akahori, Mater. Sci. Eng. A 371, 283 (2004).

[9] Y. Liu, K. Li, H. Wu, M. Song, W. Wang, N. Li, H. Tang, J. Mech. Behav. Biomed. Mater. 51, 302 (2015).

[10] H.M. Rietveld, J. Appl. Crystallogr. 3, 65 (1969).

[11] D.B. Wiles, R.A. Young, J. Appl. Cryst. 14, 149 (1981).

[12] The Rietveld Method, Ed. R.A. Young, Oxford Univ. Press, New York 1993.

[13] R.J. Hill, C.J. Howard, J Appl. Crystallogr. 20, 467 (1987).

[14] G. Dercz, D. Oleszak, K. Prusik, L. Pająk, Rev. Adv. Mater. Sci. 8, 764 (2008).

[15] G.K. Williamson, W.H. Hall, Acta Metall. 1, 22 (1953).

[16] L. Lü, M.O. Lai, Mechanical Alloying, Kluwer Academic, Boston 1998. 